\title{
Changes in Tumor Growth and Metastatic Capacities of J82 Human Bladder Cancer Cells Suppressed by Down-Regulation of Calreticulin Expression
}

\author{
Yi-Chien Lu, ${ }^{*}$ Chiung-Nien Chen, ${ }^{\dagger}$ Bojeng Wang, ${ }^{*}$ \\ Wen-Ming Hsu, ${ }^{\dagger}$ Szu-Ta Chen, ${ }^{\ddagger}$ King-Jen Chang, ${ }^{\S}$ \\ Cheng-Chi Chang, ${ }^{\text {" }}$ and Hsinyu Lee ${ }^{* \| * *}$ \\ From the Institute of Zoology,* the Graduate Institute of Oral \\ Biology, "T School of Dentistry, the Department of Life Science," \\ and the Research Center for Developmental Biology and \\ Regenerative Medicine,** National Taiwan University, Taipei; the \\ Department of Surgery, ${ }^{\dagger}$ Angiogenesis Research Center, National \\ Taiwan University Hospital and College of Medicine, Taipei; the \\ Department of Pediatrics, ${ }^{\ddagger}$ National Taiwan University Hospital \\ and National Taiwan University Hospital Yun-Lin Branch, \\ Taipei; and the Department of Surgery, ${ }^{\S}$ Cheng Ching Hospital, \\ Taichung, Taiwan
}

Bladder cancer is a common urothelial cancer. Through proteomic approaches, calreticulin (CRT) was identified and proposed as a urinary marker for bladder cancer. CRT is a multifunctional molecular chaperone that regulates various cellular functions such as $\mathrm{Ca}^{2+}$ homeostasis and cell adhesion. CRT is overexpressed in various cancers, but its mechanism of action in the development of bladder tumors remains unclear. We generated $\mathbf{J 8 2}$ bladder cancer cells lines that either stably overexpressed or knocked down CRT to investigate the physiological effects of CRT on bladder tumors. Compared with the transfected control vector cells, the knockdown of CRT suppressed cell proliferation, migration, and attachment, whereas overexpression of CRT enhanced cell migration and attachment. We further demonstrated that the phosphorylation status of focal adhesion kinase and paxillin, important regulators of the focal adhesion complex, was also regulated in these cells. In contrast, phosphorylation of Src, a protein tyrosine kinase reported to be affected by CRT, was not significantly different between the control and CRTRNAi groups. Most importantly, we observed that tumors derived from J82 CRT-RNAi cells were significantly smaller and had fewer metastatic sites in the lung and liver in vivo than did transfected control vector cells. In conclusion, our results suggest that alteration of CRT expression levels might affect bladder cancer progression in vitro and in vivo. (AmJ Pathol 2011, 179:1425-1433; DOI: 10.1016/j.ajpath.2011.05.015)

In the United States, bladder cancer was among the top 10 most frequently diagnosed cancers in 2009. ${ }^{1}$ The most common type of bladder cancer is transitional cell carcinoma, a malignant tumor that grows from the epithelium of the bladder. Approximately $30 \%$ of patients present with a muscle-invasive metastasis at the time of diagnosis, and $85 \%$ of these patients will die of the disease within 2 years if left untreated. ${ }^{2}$ This means that metastasis is one of the leading causes of cancer-related death for patients with bladder cancer. Tumor cells detach, invade, and disseminate to other sites and form secondary tumors during metastasis. Each step involves many molecules, including celladhesion molecules, matrix degradation enzymes, and various growth factors. ${ }^{3}$ However, the gene that regulates metastasis in bladder cancer is still unclear.

Calreticulin (CRT) is a 46-kDa multifunctional molecular chaperone protein in the endoplasmic reticulum (ER) that is conserved in various species. ${ }^{4}$ CRT functions have been implicated in $\mathrm{Ca}^{2+}$ homeostasis, signaling transduction, gene expression, and glycoprotein folding. ${ }^{5-7}$

Supported by the Frontier and Innovative Research Division of National Taiwan University (98R0318) and by grants (NSC97-2311-B-002-002MY3 and NSC99-2120-M-002-004) from the National Science Council of the ROC (H.L.).

Accepted for publication May 12, 2011.

Y.-C.L. and C.-N.C. contributed equally to this work.

Supplemental material for this article can be found at http://ajp. amjpathol.org or at doi: 10.1016/j.ajpath.2011.05.015.

Address reprint requests to Hsinyu Lee, Ph.D., Department of Life Science, National Taiwan University, 1 Roosevelt Rd., Sec. 4, Taipei 106, Taiwan, Republic of China; or Cheng-Chi Chang, Ph.D., Department: Graduate Institute of Oral Biology, School of Dentistry, 1 Chang-Te St., Taipei, Taiwan 100, Republic of China. E-mail: hsinyu@ntu.edu.tw or ccclrc@gmail.com. 
Many studies elucidated that the alteration of CRT levels affects cell adhesion ability. ${ }^{8-10}$ Cells with overexpressed CRT have increased adhesiveness; in contrast, knockdown of CRT suppresses adhesion. ${ }^{11-13}$ Moreover, it was also reported that activation of matrix metalloproteinase 2 , which plays an important role in cancer invasion and metastasis, increases as a result of CRT overexpression in rhabdomyosarcoma cells. ${ }^{14}$

In some cancers, tumor tissues express higher levels of CRT compared with normal tissues. CRT expression is significantly up-regulated in hepatoma, prostate, colon, and vaginal cancers. ${ }^{15-18}$ Furthermore, not only do CRT levels increase in urinary cancer tissues, but they also act as a biomarker for bladder cancer. ${ }^{19,20}$ In addition to being overexpressed in tumor tissues, CRT also regulates cancer cell behavior. Chen et al ${ }^{21}$ showed that the overexpression of CRT increased cell proliferation and migration and modulated several molecules related to cancer metastasis and angiogenesis, such as connective tissue growth factor, vascular endothelial growth factor, and placenta growth factor. ${ }^{21}$ These results indicate that CRT expression might play a crucial role in cancer progression.

Although higher levels of CRT are found in urinary cancer tissues and urinary CRT can be used as a biomarker for detection of bladder cancer, the mechanism of CRT in bladder cancer is still poorly understood. To evaluate the metastatic behavior of bladder tumor, we used an aggressive bladder cancer cell line J82 to investigate the roles of CRT on progression of bladder cancer. ${ }^{22}$ In this study, we established CRT overexpressed and knockdown stable cell lines in J82 cells to clarify the role of CRT in bladder cancer. We demonstrated that knockdown of CRT suppressed cell proliferation, attachment, and migration in bladder cancer; contrarily, overexpression of CRT enhanced cell attachment and migration. Furthermore, we showed that CRT downexpression in bladder cancer diminished tumor formation and metastasis in vivo. Our results provide evidence that CRT plays an important role in progression of bladder cancer.

\section{Materials and Methods}

\section{Cell Culture}

The J82 human bladder cancer cell line was purchased from American Type Culture Collection (Manassas, VA). Cells were cultured in Dulbecco's modified Eagle's medium and supplemented with 10\% fetal bovine serum under a humidified atmosphere of $95 \%$ air and $5 \% \mathrm{CO}_{2}$ at $37^{\circ} \mathrm{C}$. For the subcultures, cells were trypsinized with 0.05\% EDTA-trypsin.

\section{Construction of Inducible Cell Lines}

To set up a tetracycline-inducible CRT system, the pEYFP-N1 was subcloned into pcDNA5/TO (Invitrogen, Camarillo, CA) by Kpnl and Notl to generate pcDNA5/TO-YFP (\#5y) used as control. CRT was amplified from HEK293 cDNA and subcloned into pcDNA5/TO-YFP to generate pcDNA/TO-ss-YFP-CRT (\#5yCRT) by the following primers: ss-forward-Nhel, 5'-CCGCTAGCTTGATGCTGCTATCCGT-
GCCGCTGC-3', ss-reverse-HindIII, 5'-CCAAGCTTGGCGACGGCCAGGCCGAGGA-3'; YFP-forward-HindllI, 5'-CCAAGCTTGTGAGCAAGGGCGAGGAGCT-3', YFP-reverseKpnl, 5'-AAGGTACCCTTGTACAGCTCGTCCATGC-3'; CRT-forward-Kpnl, 5'-AAGGTACCGAGCCCGCCGTCTACTTCAA-3', and CRT-reverse-Xbal, 5'-AATCTAGACTACAGCTCGTCCTTGGCCTGG-3' .

\section{Transfection and Selection of Stable Cell Lines}

For transfection experiments, J82 cells were plated $2 \times$ $10^{5} \mathrm{cells} /$ well in 6-well plates, and $2 \mu \mathrm{g}$ of plasmid DNA for CRT overexpression ("5y and "5yCRT) or knockdown (pCR3.1 and CRT-RNAi) was transfected into cells with the use of $10 \mu \mathrm{L}$ of Lipofectamine TM2000, (Invitrogen). For single-cell selection, the transfected J82 cells were passaged at a 1:10 dilution in 10-cm culture plate at 2 days after transfection, and the stable cells were picked from a single colony with the use of cloning rings. Medium with antibiotics $\left(200 \mu \mathrm{g} / \mathrm{mL}\right.$ Hygromycin for ${ }^{\#} 5 y$ and ${ }^{*} 5 \mathrm{yCRT}$ inducible clones and $700 \mu \mathrm{g} / \mathrm{mL}$ G418 for pCR3.1 and CRT-RNAi stable clones) was replaced every 2 or 3 days. Two months later, antibiotic-resistant single clones were selected and amplified to test CRT mRNA and protein expressions. The inducible YFP, ss-YFP-CRT cell lines ( ${ }^{* 5 y}$ and ${ }^{\#} 5 \mathrm{yCRT}$ ) were pretreated with $1 \mu \mathrm{g} / \mathrm{mL}$ tetracycline for 48 hours to perform the experiments.

\section{Image Analysis}

For analysis of cell shape, morphologic images of J82 cells were thresholded and outlined with the use of MetaMorph software (Sunnyvale, CA). Changes in cell shape were assessed by a shape factor $\left(\mathrm{sf}=4 \mathrm{~A} / \mathrm{p}^{2}\right)$ calculated from the area and the perimeter of the delineated object. Value close to "1" represents a flat object, whereas a value close to " 0 " represents a circular object.

\section{Immunoblotting}

Cells were plated at $2 \times 10^{5}$ cells/well in six-well plates overnight. For harvesting cell lysates, cells were washed with cold PBS and lysed with radioimmunoprecipitation assay buffer [50 mmol/L Tris ( $\mathrm{pH} 7.0), 150 \mathrm{mmol} / \mathrm{L} \mathrm{NaCl}$, $1 \%$ Triton $\mathrm{X}-100,0.5 \%$ sodium deoxycholate, and $0.1 \%$ SDS ( $\mathrm{pH}$ 7.4)] containing protease inhibitors. Equal amounts of each sample $(30 \mu \mathrm{g})$ were boiled with $6 \times$ sample buffer for 5 minutes and resolved by 10\% SDSPAGE. After electrophoresis, the gel was transferred to a polyvinylidene difluoride membrane. Membranes were blocked by $5 \%$ bovine serum albumin in $10 \mathrm{mmol} / \mathrm{L}$ Tris, $150 \mathrm{mmol} / \mathrm{L} \mathrm{NaCl}$, and $0.1 \%$ Tween-20 (pH 7.4) at room temperature for 2 hours. Blocked membranes were incubated with the following primary antibodies: CRT, Upstate Biotechnology (Lake Placid, NY) and Santa Cruz Biotechnology (Santa Cruz, CA); paxilln (pY118), Cell Signaling (Danvers, MA); focal adhesion kinase (FAK; pY397), Invitrogen; FAK, paxillin, c-Src, and actin, Santa Cruz Biotechnology; and Src (pY418), Biosource, for 2 hours or $4^{\circ} \mathrm{C}$ overnight. Membranes were washed and then incubated with horseradish peroxidase-conjugated second- 
ary antibodies (1: 5000) for 1 hour. Immunoreactive bands were quantified with TotalLab software version 2.01 (Durham, NC).

\section{RNA Isolation and Real-Time PCR}

Total RNA were isolate by the TRIzol reagent, following the manufacturer's instructions. RT-PCR was performed with ReverTra Ace reverse transcriptase. Real-time PCR was performed with the $i C y c l e ~ i Q$ real-time detection system (Bio-Rad, Hercules, CA) with the DNA double-strand specific SYBR Green I dye for detection. Cycling condition was $95^{\circ} \mathrm{C}$ for 15 minutes, followed by 40 cycles of $95^{\circ} \mathrm{C}$ for 30 seconds, $60^{\circ} \mathrm{C}$ for 30 seconds, and $72^{\circ} \mathrm{C}$ for 30 seconds. For quantification, the target gene was normalized to glyceraldehyde-3-phosphate dehydrogenase (GAPDH), an internal control gene. Primer sequences were forward 5'-GGTGGTCTCCTCTGACTTCAAC-3' and reverse 5'-TCTCTCTTCCTCTTGTGCTCTTG-3' for GAPDH and forward 5'-AAGTTCTACGGTGACGAGGAG-3' and reverse 5'-GTCGATGTTCTGCTCATGTTTC-3' for CRT.

\section{Cell Cycle Analysis and Proliferation Assay}

Cells were starved overnight and then treated with cultured medium (Dulbecco's modified Eagle's medium with $10 \%$ fetal bovine serum) for 10 hours. Cells were trypsinized and resuspended in $1 \mathrm{~mL}$ of PBS. Propidium iodide was added to the suspensions and then incubated in a $37^{\circ} \mathrm{C}$ water bath for 20 minutes in the dark. Propidium iodide-stained cells were analyzed by flow cytometry, and the percentages of different phases were automatically analyzed by Partec FloMax software (Münster, Germany). To estimate cell proliferation rate, cells were plated in triplicates at 2500 cells/well in 96-well plates. Ten microliters of $5 \mathrm{mg} / \mathrm{mL}$ MTT was added to each well at 24, 48, and 72 hours after plating. After incubation for 4 hours at $37^{\circ} \mathrm{C}$, MTT-containing medium was removed. MTT metabolic products were subsequently dissolved in $100 \mu \mathrm{L}$ of dimethyl sulfoxide for 20 minutes at $37^{\circ} \mathrm{C}$, followed by measurement of absorbance at $550 \mathrm{~nm}$.

\section{Cell Migration Assay}

Migration rates of different cell lines were assayed in a modified Boyden's chamber (Neuro Probe, Gaithersburg, $\mathrm{MD})$. Cells suspended in $50 \mu \mathrm{L}\left(1.5 \times 10^{4}\right.$ cells/well) were loaded in the upper chamber. Dulbecco's modified Eagle's medium and fetal bovine serum were loaded in the lower chamber as the negative control and chemoattractant, respectively. After 4 hours, migrating cells were fixed and quantified by a colorimetric measurement with the use of crystal violet staining with TotalLab v2.01 software.

\section{Cell Attachment Assay}

The 96-well culture plates were coated with $10 \mu \mathrm{g} / \mathrm{mL}$ collagen I and incubated at $37^{\circ} \mathrm{C}$ for 30 minutes followed by a PBS wash. Cells $\left(5 \times 10^{4}\right.$ cells $\left./ 100 \mu \mathrm{L}\right)$ were seeded in the well and incubated at $37^{\circ} \mathrm{C}$ for 20 minutes. After removing the medium and non-attached cells, wells were washed with PBS, and $0.1 \%$ crystal violet was added for 10 minutes. The plate was gently washed with PBS three times. Then 10\% acetic acid was added for 20 minutes, and the plate was read at $550 \mathrm{~nm}$.

\section{Apoptosis Detection Assay}

Cells were starved overnight and treated with $5 \mu \mathrm{g} / \mathrm{mL}$ actinomycin D (Sigma, St. Louis, MO) as positive control for 24 hours. Cell apoptosis rate was detected with the use of fluorescein isothiocyanate Annexin $\mathrm{V}$ apoptosis detection kit I (BD Pharmingen, San Diego, CA). Cells were trypsinized and resuspended in $100 \mu \mathrm{L}$ of $1 \times$ binding buffer. Fluorescein isothiocyanate, Annexin V, and propidium iodide ( $5 \mu \mathrm{L}$ ) were added to the suspensions and then incubated for 20 minutes at room temperature in the dark. Annexin $\mathrm{V}$-stained cells were analyzed by flow cytometry. To measure end-stage apoptosis, TUNEL labeling was performed in tumor sections of the two groups with the use of a DNA fragmentation detection kit (Calbiochem, Gibbstown, NJ), following manufacturer's instructions. Each section had been chosen for five images, and TUNEL-positive cells were quantified under microscope by high-power field (magnification, $\times 200$ ). For a positive control, sections were incubated in DNase I before the addition of equilibration buffer, whereas double distilled water was used instead of terminal deoxynucleotide transferase reaction mix in the negative control.

\section{Subcutaneous Injection Model}

For models of bladder cancer to measure tumorigenicity, 8-week-old male BALB/c nude mice $(n=10$; National Defense Medical Center, Taipei, Taiwan) were housed in pathogen-free conditions and acclimatized for 1 to $\sim 2$ weeks. Mice were randomized to one of two groups and were subcutaneously injected with vector control $(n=5)$ and CRT-RNAi $(n=5)$ cells in the inguinal region. Cells $\left(1 \times 10^{7}\right)$ were suspended in PBS and Matrigel in a 1:1 $(v / v)$ ratio. Tumors were measured every 3 days (width ${ }^{2} \times$ length $\times 0.5$ ). Mice were sacrificed after 45 days, and subcutaneous tumors were surgically excised.

\section{Tail Vein Injection Model}

For the metastasis model, 8-week-old male severe combined immunodeficient mice ( $n=12$; BioLASCO, Taipei, Taiwan) were used for tail vein injection. Cells $\left(10^{6}\right)$ suspended in PBS were injected through the tail vein. After 40 days, the lungs and liver were resected and fixed in 3.7\% formalin for paraffin embedding in preparation for immunohistochemical analysis. The percentage of the lung metastasis area was calculated as the metastatic lung area/total lung area.

\section{Statistical Analysis}

Data were statistically analyzed with one-way analysis of variance, followed by Fisher's protected least-significant difference test (StatView; Abacus Concept, Berkeley, 
A

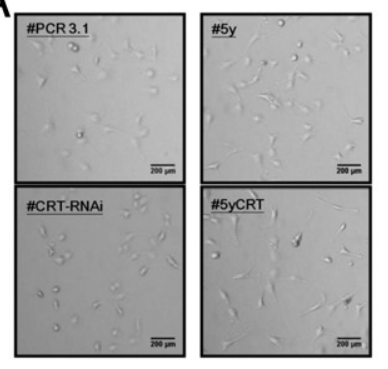

B

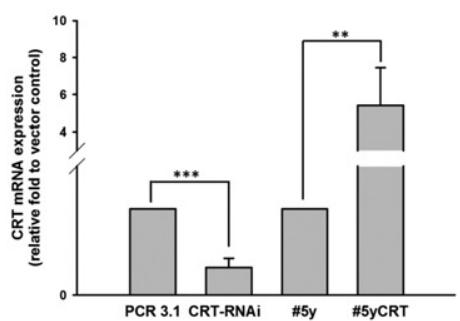

C

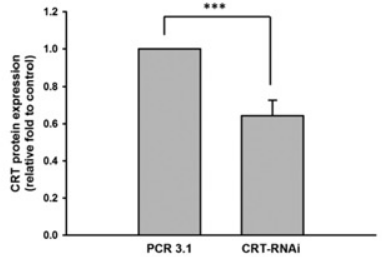

D

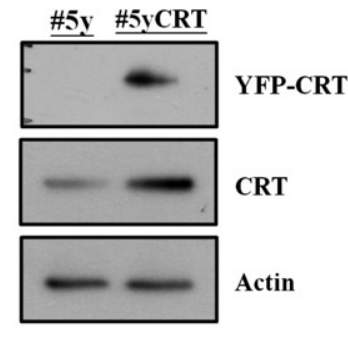

Figure 1. J82 bladder cancer cells were stably transfected with CRT overexpressing and RNAi plasmids. A: Cell morphology of CRT in differentially expressed cell lines in serum-containing medium. ${ }^{*} 5 \mathrm{y}$ and ${ }^{*} 5$ yCRT cells were stimulated with $1 \mu \mathrm{g} / \mathrm{mL}$ tetracycline for 48 hours to induce CRT expression. Scale bar $=200$ $\mu \mathrm{m}$. B: mRNA expressions were confirmed by real-time PCR in CRT knockdown and overexpression stable cell lines. CRT mRNA expression was normalized to the internal control, GAPDH. C: Western blot analysis shows protein expression in CRT-RNAi stable cell lines. The human $\beta$-actin level was used as a loading control. D: An endogenous CRT protein band $(\sim 60 \mathrm{kDa})$ was both detected in ${ }^{*} 5 \mathrm{y}$ and ${ }^{*} 5 \mathrm{yCRT}$ cells. An exogenous YFP-CRT fusion protein $(\sim 87 \mathrm{kDa})$ was only detected in ${ }^{*} 5 y C R T$ cells. All of the results are repeated in at least three independent experiments. Each bar of the histogram represents quantified results and are shown as the mean \pm SD. Statistical differences were compared with the control level $\left({ }^{*} P<0.01,{ }^{* * *} P<0.001\right)$.

CA). Each result was obtained from at least three independent experiments, and a value of $P<0.05$ was considered statistically significant.

\section{Results}

\section{Generation of Stable Cell Lines}

To clarify the effects of CRT in bladder cancer cells, we attempted to select CRT overexpression and knockdown stable cell lines. J82 bladder cancer cells were transfected with a CRT overexpressed plasmid and a CRTRNAi plasmid and then selected by respective antibiotics. After selection by G418 over 2 months, CRT-RNAi cells were generated, and CRT knockdown efficiency was confirmed with a real-time PCR and Western blotting to detect mRNA (Figure 1B) and protein (Figure 1C) expression levels compared with the transfected control vector cells (pCR3.1). However, during the stable cell line selection, constitutive overexpression of CRT resulted in cell spreading (see Supplemental Figure S1A at http:// ajp.amjpathol.org) followed by cell death within 2 weeks. Therefore, an inducible-CRT bladder cancer cell line was generated by tetracycline-regulated gene system. Cells were treated with $1 \mu \mathrm{g} / \mathrm{mL}$ tetracycline for 48 hours to induce CRT mRNA and protein expressions (Figure 1, B and D). Cell morphology was shown in Figure $1 \mathrm{~A}$, and the shape factors calculated by MetaMorph software were not significantly different between pCR3.1 and CRT-RNAi or between ${ }^{*} 5 y$ and ${ }^{*} 5 y C R T$ cells (see Supplemental Figure S1B at http://ajp.amjpathol.org).

\section{Cell Proliferation Rate Is Lower in CRT Knockdown Cells}

To understand how CRT regulates cell behavior, we used functional assays to investigate the physiological effects of CRT expression in bladder cancer cells. Their cell cycle was analyzed by flow cytometry. In these assays, the CRTRNAi group showed more cells arrested in the $G_{1}$ phase $(41 \%)$ than the control group (30\%), which indicated that CRT knockdown suppressed cell proliferation (Figure 2A, left panel). Nevertheless, our results showed that there was no significant difference between ${ }^{\#} 5 y$ and ${ }^{\#} 5 y C R T$ (Figure $2 \mathrm{~A}$, right panel). Cell proliferation rate was also assessed by MTT assays over several time points after plating. The MTT readings for CRT-RNAi cells were significantly lower than the MTT readings from control cells (pCR3.1) at 24, 48, and 72 hours (Figure 2B, left panel). However, no significant difference was observed between CRT overexpressed cells
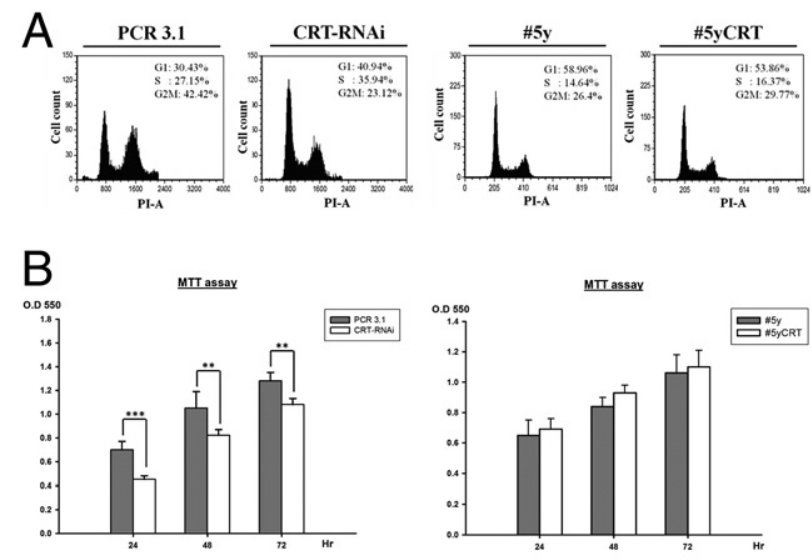

\section{C}
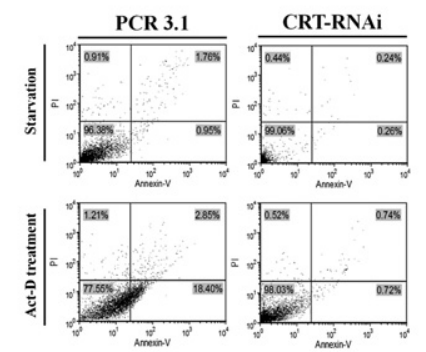

Figure 2. Knockdown of CRT altered the proliferation rate of bladder cancer cells. A: The cell cycle was analyzed by flow cytometry. Left: CRT-RNAi cells showed proportionally more cells in the $G_{1}$ phase than the $S$ and $G_{2} M$ phases compared with the vector control group (pCR3.1). Right: Cells that induced CRT expression did not promote cell cycle transit. B: Cell proliferation was determined by MTT assay. Cells ( 2500 cells/well) were seeded in 96-well plate Cell numbers were determined by measuring the absorbance of $550 \mathrm{~nm}$ at 24 , 48, and 72 hours after plating. C: Apoptosis was evaluated after starvation for 24 hours and stained with Annexin V. Treatment of actinomycin-D (act-D; $5 \mu \mathrm{g} / \mathrm{mL}$ ) is used as positive control. The number showed the percentage of early apoptotic cells (lower right quadrant). These results were confirmed by at least three independent experiments $\left({ }^{*} P<0.01\right.$, $\left.{ }^{* *} P<0.001\right)$ 

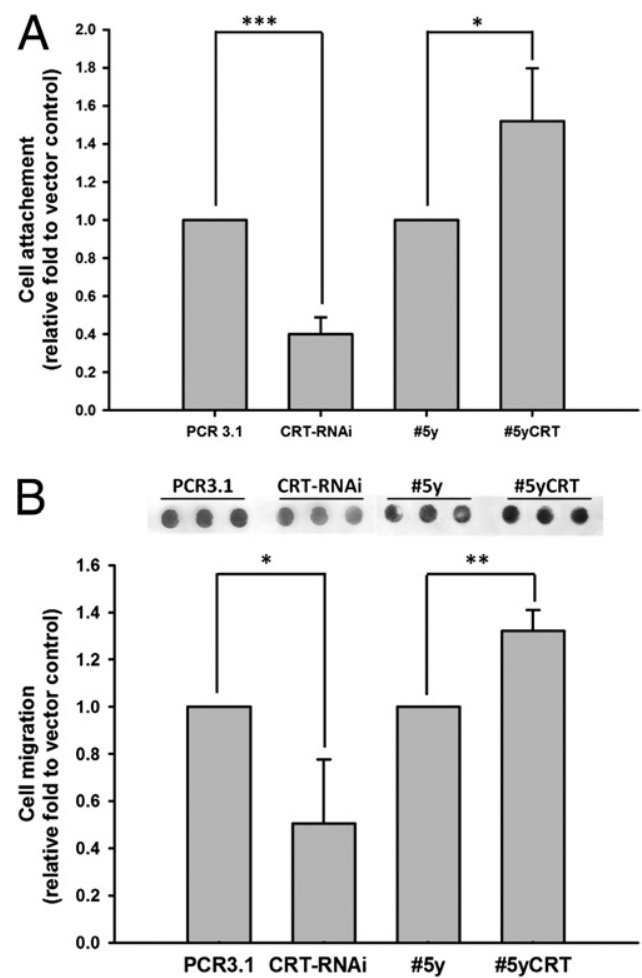

Figure 3. Cell adhesion and migratory ability were regulated by CRT expression levels. A: Cells $\left(5 \times 10^{4}\right.$ cells $\left./ 100 \mu \mathrm{L}\right)$ were seeded in 96-well collagen-coated (10 $\mu \mathrm{g} / \mathrm{mL}$ ) plates for 20 minutes. Compared with transfected control vector cells, CRT-RNAi cells adhered poorly to type-I collagen. Cells with higher CRT levels showed a stimulation of attachment to type-I collagen. B: Cells $\left(1.5 \times 10^{4} \mathrm{cells} / \mathrm{well}\right)$ were loaded into the upper chamber of a modified Boyden's chamber, and fetal bovine serum was loaded into the lower chamber as a chemoattractant for cells. After 4 hours, CRT-RNAi cells had migrated significantly slower than control (pCR3.1) cells, and ${ }^{*} 5$ yCRT cells exhibited an opposite effect than its control ( $\left.{ }^{5} 5 \mathrm{y}\right)$ cells. One of three independent experiments, performed in triplicate, is shown. Each bar of the histogram represents quantified results and is shown as the mean \pm SD. Statistical differences were compared with the control level $\left({ }^{*} P<0.05\right.$, ${ }^{* * * *} P<0.01$, and ${ }^{* * * * * *} P<$ $0.001)$.

and vector-transfected cells (Figure $2 \mathrm{~B}$, right panel). To estimate whether the decreasing numbers in the CRT-RNAi group was because of apoptosis, we used Annexin V/propidium iodide staining to determine the apoptotic cells. pCR3.1 and CRT-RNAi cells were starved for 24 hours. Actinomycin-D, which is a potent inducer for apoptosis in several cell lines, ${ }^{23}$ was used as positive control. As shown in Figure $2 \mathrm{C}$, the percentage of Annexin $\mathrm{V}$-positive cells were $<3 \%$ in both pCR3.1 and CRT-RNAi cells, which indicated that knockdown of CRT did not induce apoptosis in J82 cells. These results justified that down-regulation of CRT inhibited proliferation of bladder cancer cells rather than induction of apoptosis.

\section{Alteration of CRT Levels Affects Cell Attachment and Migration}

We also used cell migration and attachment assays to explore the effect of CRT levels in J82 cancer cells. Equal numbers of cells were seeded on a collagen-coated plate for 20 minutes. Results showed that the attachment ability of the cell was suppressed in CRT-RNAi cells compared with transfected vector control cells (Figure 3A, bars 1 and 2). On the contrary, CRT overexpression enhanced cell attachment significantly than vector control cells (Figure 3A, bars 3 and 4). To determine whether the effects of CRT are universal to bladder cancer, we used another bladder cancer cell line to perform our experiments. Down-regulation of CRT in T24 bladder cancer cells also suppressed cell attachment to type-I collagen (see Supplemental Figure S2 at http://ajp.amjpathol.org), suggesting that the effects of CRT we observed are not only specific to $\mathrm{J} 82$ cell line. Furthermore, with the use of the modified Boyden chamber method, J82 cells with low CRT expression had lower migration capacities than control cells (Figure 3B, bars 1 and 2), and cells with higher CRT expression showed an opposite effect (Figure 3B, bars 3 and 4). Consequently, these results showed a positive correlation between CRT expression levels and cell attachment and migration in bladder cancer cells.

\section{Phosphorylation Levels of FAK and Paxillin Are Lower in CRT Knockdown Cells}

Papp and others ${ }^{12,13}$ reported that altering CRT expression in fibroblasts can affect cell motility and adhesion through
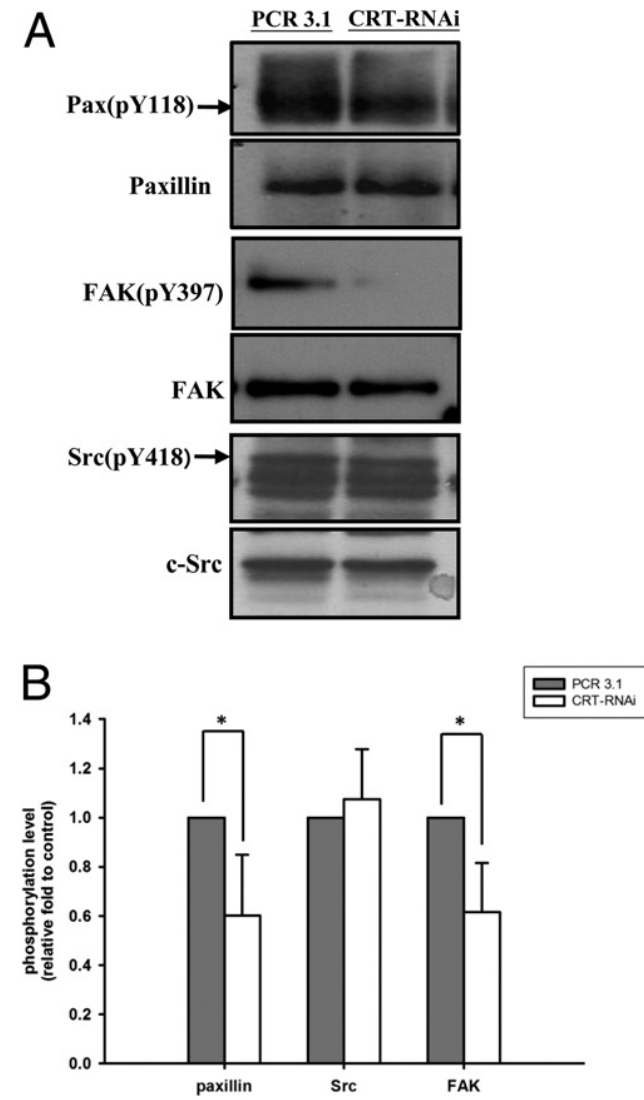

Figure 4. Phosphorylation levels of FAK and paxillin were decreased in CRT knockdown cells. A: Western blot analysis indicated that the phosphorylation levels of paxillin and FAK were more down-regulated in CRT-RNAi cells than in control cells. The proportion of phosphorylated Src was not altered in CRT-RNAi cells. B: Quantitative results of the phosphorylated ratios of paxillin, FAK, and Src were normalized by each total protein expressions. One of three independent experiments was shown. Each bar of the histogram represents quantified results and is shown as the mean \pm SD. Statistical differences were compared with the control level $\left({ }^{*} P<0.05\right)$. 


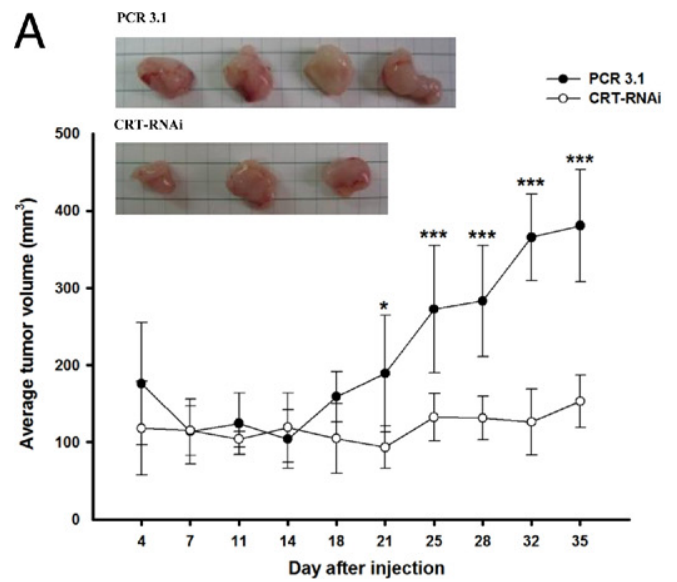

B
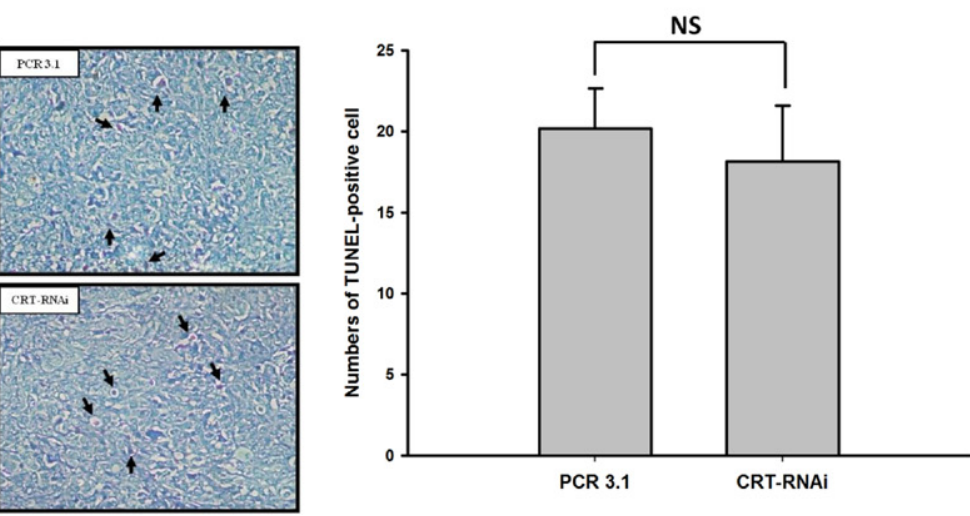

Figure 5. Knockdown of CRT diminishes tumor formation in nude mice. A: Mice were subcutaneously injected with vector control cells (closed circles) or CRT-RNAi cells (open circles), and tumor sizes were measured over time. After 20 days, tumor sizes significantly differed between the two groups. Knockdown of CRT suppressed tumorigenesis in bladder cancer cells. B: Determination of TUNEL-positive cells for injection of cells from mice (high power field, $\times 200$ ). The arrows indicate the positive cells. No significant difference was observed between the two groups. Each bar of the histogram represents quantified results of the TUNEL-positive/field and is shown as the mean \pm SD.

regulating c-Src and FAK activity. Paxillin is one molecule of the focal adhesion complex which regulates the cell adhesion mechanism. On the basis of those previous studies, we used Western blotting to analyze the downstream signaling pathway affected by CRT in our system. Phosphorylation levels of Src (pY418), FAK (pY397), and paxillin (pY118) were also examined. As shown in Figure 4 , the phosphorylation levels of FAK $(-40 \%)$ and paxillin $(-40 \%)$ decreased in CRT knockdown cells, whereas no difference in Src phosphorylation was observed.

\section{Knockdown of CRT Inhibits Tumor Growth in Vivo}

Stably transfected cells were subcutaneously injected into nude mice to determine the effects of CRT on tumor growth. Tumor volumes were measured every 3 days. Compared with tumors of control mice, tumors of mice injected with CRT-RNAi were significantly smaller after 21 days. The mean volume of tumors of CRT-RNAi clones was suppressed $60 \%$ more than that of control clones at day 35 (Figure 5A). Moreover, we further determined the end-stage apoptosis in the injection of cells from nude mice. Tumor sections from both groups were analyzed by TUNEL assays. The number of TUNEL-positive cells in the control group was not significantly increased in comparison to the CRT-RNAi group (Figure 5B). These results are consistent with our observations in vitro.

\section{Knockdown of CRT Inhibits Metastasis of Bladder Cancer Cells}

In addition, we further confirmed that the metastatic capacity was lower in the CRT-RNAi subcutaneous injection model. After sacrificing the mice, we found metastatic nodules in the liver of control mice but not in CRT-RNAiinjected mice (Figure 6A). These results strongly suggest that expression levels of CRT are closely related to the metastatic behavior of bladder cancer cells. To further confirm this hypothesis, we performed a tail vein injection

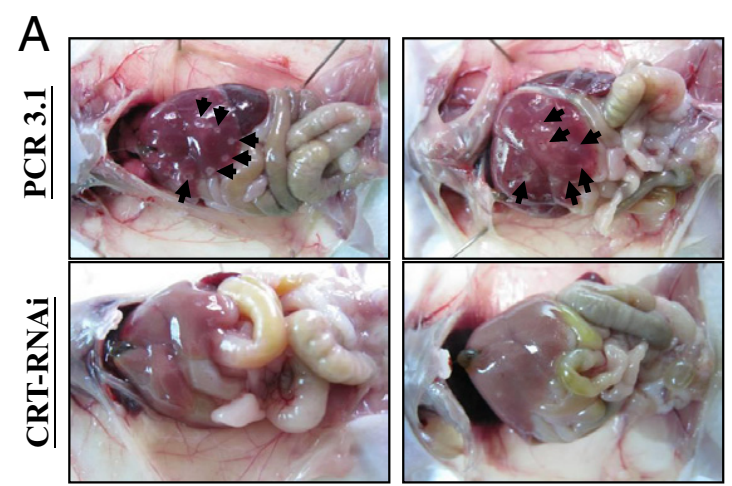

$B$
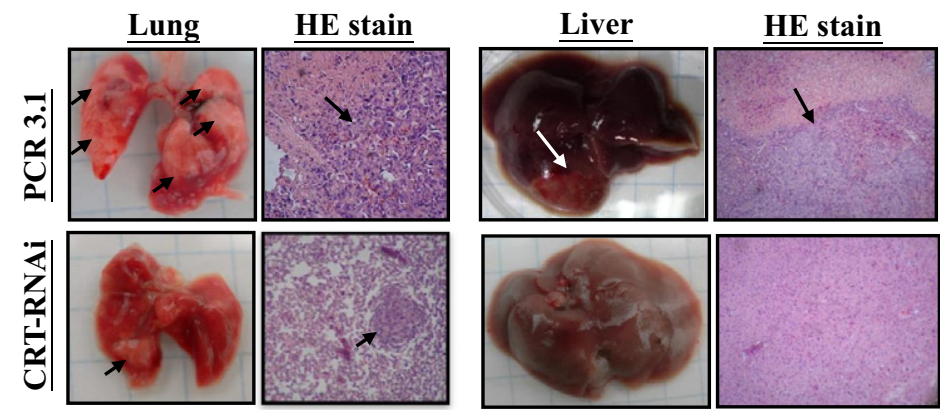

Figure 6. Knockdown of CRT inhibits metastasis of bladder cancer cells. A: Nude mice were subcutaneously injected with $10^{7}$ cells and sacrificed after 45 days There were obvious metastatic nodules in the liver of the control group (shown by arrows) but not in the CRT-RNAi group. B: Lung and liver metastases were performed by an intravenous injection. In total, $10^{7}$ cells (control and CRT-RNAi) were injected into the tail vein of severe combined immunodeficient mice $(n=5$ and $n=7$, respectively). After 40 days, both groups had lung metastases, but the area of lung metastasis was higher in the control group. Liver metastasis was only observed in control mice. 
Table 1. Lung and Liver Metastatic Incidence in CRT-Stable Cell Lines

\begin{tabular}{cccccccc}
\hline & 1 & 2 & 3 & 4 & 5 & 6 & 7 \\
\hline PCR 3.1 & & & & & & & \\
$\quad$ Lung & ++ & + & + & +++ & + & & \\
Liver & + & NT & + & NT & NT & & \\
$\begin{array}{c}\text { CRT-RNAi } \\
\text { Lung }\end{array}$ & + & + & NT & + & + & + & NT \\
Liver & NT & NT & NT & NT & NT & NT & NT \\
\hline
\end{tabular}

Metastatic area is indicated by the following,$+<25 \%$;,$++ \geq 25 \%$; ,$+++>40 \%$.

NT, no tumor.

experiment, which is a specific model used to investigate cancer cell metastasis. Liver metastasis was observed to be at $40 \%$ (2 of 5) in the control group and at 0\% (0 of 7 ) in the CRT-RNAi group. In comparison, $100 \%$ (5 of 5 ) of control cells and $71 \%$ (5 of 7 ) of CRT-RNAi-injected mice developed lung metastasis. Although lung metastasis was observed in both groups, the percentage of metastatic areas was much higher in the control group (Figure 6B; see also Supplemental Figure S3 at http://ajp.amjpathol.org). From the two mice models, we can conclude that vector control cells induced tumor formation and visible liver and lung metastasis, whereas CRT-RNAi cells formed smaller tumors and fewer metastatic nodules in the liver and lungs. These results are summarized in Table 1.

\section{Discussion}

CRT is well established as a multifunctional protein that regulates cell behavior. ${ }^{4}$ In recent studies, it was shown that CRT is located in the cytosol and extracellular environments and on cell surfaces to modulate diverse physiological and pathologic effects. ${ }^{24}$ Many researchers reported that in some cancers CRT is up-regulated in tumor tissues more often than in normal tissues. Kageyama et $\mathrm{al}^{19}$ also identified that CRT levels are higher in urothelial tissues of patients with bladder cancer, and that urinary CRT can act as a biomarker for detection of bladder cancer. In this study, we surveyed the ability of CRT knockdown bladder cancer cells to suppress cell proliferation, migration, and adhesion. We further proved that in vivo downexpression of CRT diminishes tumorigenesis and metastasis of bladder cancer.

$\mathrm{ER}$ is one of the important organelles for protein folding. Some studies showed that abnormal expression of CRT, an ER-resident chaperon, would trigger unfolded protein response that results in ER stress. ${ }^{25,26}$ In the present study, overexpressing CRT in bladder cancer caused morphologic changes and cell death within 2 weeks. These changes are consistent with a previous study showing that albumin-induced ER stress caused a conversion to the spindle-like morphology in tubular cells. ${ }^{27}$ Therefore, we surmised that constitutively high levels of CRT expression might disturb the ER stress regulation and lead to cells to exhibit an abnormal morphology.

The N-terminal fragment of CRT, vasostatin, is an antiangiogenic factor and inhibits endothelial cell proliferation. ${ }^{28,29}$ This protein was implied to be an inhibitor of lung tumor growth and metastasis in different mouse models. ${ }^{30}$ However, there is no current study exploring the effects of vasostatin in bladder cancer. Previous studies have showed that CRT affects nuclear localization and activities of p53, which subsequently leads to apoptosis and cell-cycle arrest. ${ }^{31,32}$ In this study, inducible CRT expression in $\mathrm{J} 82$ cells by tetracycline-regulated gene system did not enhance cell proliferation. We surmised that it might be because of the short induction time (only 48 hours) for J82 cells to enhance CRT expression transiently, which might not have profound effects on cell proliferation. Nevertheless, there is a decreased cell proliferation rate in the J82 CRT-RNAi cell line which has been down-regulated of CRT stably. This correlates with another study showing that exogenous addition of CRT stimulates human keratinocyte and fibroblast proliferation. ${ }^{33}$ In addition, overexpression of CRT in gastric cancer enhances cell proliferation and up-regulates the expression and secretion of the well-known pro-angiogenic factors, vascular endothelial growth factor and placenta growth factor. ${ }^{21}$ This evidence is consistent with our results showing that knockdown of CRT inhibited tumor growth in vivo. Moreover, neuroendocrine cells overexpressing vasostatin are also known to enhance malignant behaviors in a nude mice model. ${ }^{34}$ Therefore, we speculated that the effects of CRT on cell proliferation and tumorigenesis may be via regulation of the vascular endothelial growth factor signaling pathway.

Cells that adhere to extracellular matrix are regulated by various $\mathrm{Ca}^{2+}$-relative pathways. The roles of CRT in cell adhesion have been extensively studied. Different expression levels of CRT affect cell adhesiveness, motility, and spread in various cell types. ${ }^{8,9,11,35}$ In this study, we demonstrated that up-regulated CRT expression increased cell attachment to type-I collagen. Furthermore, we also verified that down-regulation of CRT suppressed that attachment of both J82 and T24 bladder cancer cells to type-I collagen. These results suggested that CRT plays an important role in regulation of bladder cancer adhesion, and this effect may not be a specific event in J82 cells. A previous study showed that CRT interacts with integrins by binding to the cytoplasmic KXGFFKR motif of the integrin $\alpha$-subunit. ${ }^{36}$ Several studies mentioned that CRT is colocalized with the $\alpha_{3} \beta_{1}$ integrin via the $\mathrm{N}$-domain, and surface CRT interacts with the collagen receptors, $\alpha_{2} \beta_{1}$ integrin and glycoprotein $\mathrm{VI}$, in human platelets. ${ }^{37,38}$ Furthermore, active integrins increase the association between CRT and $\alpha_{2} \beta_{1}$ integrin. ${ }^{39}$ Abnormal cell migration is a typical characteristic of cancer metastasis, and integrins, an important modulator for cell adhesion and migration, are involved in this process. ${ }^{40}$ Although CRT is proposed to play a suppressive role in growth and metastasis of prostate cancer, ${ }^{41}$ it was also shown that mRNA and protein expressions of CRT are elevated in highly metastatic prostate cancer cell lines. ${ }^{42}$ This indicates a possible correlation between CRT and metastasis. According to these references, we hypothesized that our observation of down-regulated CRT diminishing cell migration, adhesion, and metastatic abilities in bladder cancer cells might have been because of the reduced interaction between CRT and integrins. 
Protein tyrosine phosphorylation is a major event for the cell adhesive mechanism. ${ }^{43,44}$ Cell adhesiveness decreases in CRT-underexpressing mouse $\mathrm{L}$ fibroblasts that contain higher levels of active c-Src. ${ }^{12}$ However, the results of our experiments showed that $\mathrm{C}-\mathrm{Src}$ activity is unaltered, which led us to think that the relationship between CRT and c-Src activation may differ, depending on the type of cell. Although there was no difference in c-Src phosphorylation, we observed decreases in phosphorylation levels of other crucial focal contact proteins such as FAK and paxillin. FAK is a cytoplasmic non-receptor tyrosine kinase identified as the downstream signaling molecule of integrin-dependent cell adhesion. It is also known that the c-terminal of FAK is the binding site for the integrin-mediated protein, paxillin. ${ }^{45} \mathrm{~A}$ previous study showed that breast cancer cells with high metastatic capacity have increased mRNA expression and paxillin protein levels. ${ }^{46}$ In addition, FAK was also proven to be a key signaling factor in tumor initiation, angiogenesis, and metastasis. ${ }^{47}$ This evidence supports our data which showed that decreased CRT expression in bladder cancer inhibits cancer metastasis through regulating FAK and paxillin phosphorylation.

CRT regulates various cell behaviors which suggests that it may also play a part in cancer development. Much clinical research has shown a correlation between CRT expression levels and clinicopathologic factors in different cancers. CRT is highly expressed in gastric tumor tissues and significantly correlated with tumor serosal invasion, lymph node metastasis, and microvessel density. ${ }^{21}$ Moreover, CRT is up-regulated in bladder tumor tissues, and the concentration of urinary CRT has a tendency to increase in histologic grade and pathologic $T$ stage in bladder cancer. ${ }^{19,20}$ If a patient with bladder cancer is diagnosed with advanced-stage (T2 to T4) tumors, it means that the cancer cells possess a higher invasive ability to grow into the muscle layer and can even spread to areas outside the bladder which increases the incidence of tumor metastasis. These results provide strong evidence that supports the phenomenon of bladder cancer cells that express lower levels of CRT having diminished tumor growth and metastasis in mice models. Therefore, we concluded that CRT might play an important role in bladder cancer metastasis.

On the basis of the clinical data published by Kageyama et $\mathrm{al},{ }^{19,20}$ our results further clarify how CRT modulates the physiological mechanisms in bladder cancer progression. These findings, for the first time, provide evidence that altered CRT expression affects bladder cancer tumorigenesis and metastasis. In the future, we will attempt to investigate detailed mechanisms of CRT-mediated adhesion in bladder cancer to optimize the research modality.

\section{Acknowledgments}

We thank Ching-Ling Lin for her excellent technical assistance and Carol Chang for critically reading this article.

\section{References}

1. Jemal A, Siegel R, Ward E, Hao YP, Xu JQ, Thun MJ: Cancer statistics, 2009. CA Cancer J Clin 2009, 59:225-249

2. Prout GR, Marshall VF: The prognosis with untreated bladder tumors Cancer 1956, 9:551-558

3. Yasui W, Oue N, Aung PP, Matsumura S, Shutoh M, Nakayama H Molecular-pathological prognostic factors of gastric cancer: a review. Gastric Cancer 2005, 8:86-94

4. Michalak M, Corbett EF, Mesaeli N, Nakamura K, Opas M: Calreticulin: one protein, one gene, many functions. Biochem J 1999; 344:281-292

5. Baksh S, Michalak M: Expression of calreticulin in Escherichia-coli and identification of its Ca2+ binding domains. J Biol Chem 1991, 266:21458-21465

6. Krause KH, Michalak M: Calreticulin. Cell 1997, 88:439-443

7. Helenius A, Trombetta ES, Hebert DN, Simons JF: Calnexin, calreticulin and the folding of glycoproteins. Trends Cell Biol 1997, 7:193-200

8. Opas M, Szewczenko-Pawlikowski M, Jass GK, Mesaeli N, Michalak M: Calreticulin modulates cell adhesiveness via regulation of vinculin expression. J Cell Biol 1996, 135:1913-1923

9. Fadel MP, Dziak E, Lo CM, Ferrier J, Mesaeli N, Michalak M, Opas M: Calreticulin affects focal contact-dependent but not close contactdependent cell-substratum adhesion. J Biol Chem 1999, 274:1508515094

10. Fadel MP, Szewczenko-Pawlikowski M, Leclerc P, Dziak E, Symonds JM, Blaschuk O, Michalak M, Opas M: Calreticulin affects betacatenin-associated pathways. J Biol Chem 2001, 276:27083-27089

11. Papp S, Fadel MP, Opas M: Dissecting focal adhesions in cells differentially expressing calreticulin: a microscopy study. Biol Cell 2007, 99:389-402

12. Papp S, Fadel MP, Kim H, McCulloch CA, Opas M: Calreticulin affects fibronectin-based cell-substratum adhesion via the regulation of cSrc activity. J Biol Chem 2007, 282:16585-16598

13. Szabo E, Papp S, Opas M: Differential calreticulin affects focal contacts via the Calmodulin/CaMK II pathway. J Cell Physiol 2007, 213: 269-277

14. Ito $\mathrm{H}$, Seyama $\mathrm{Y}$, Kubota S: Calreticulin is directly involved in anti-alpha 3 integrin antibody-mediated secretion and activation of matrix metalloprotease-2. Biochem Biophys Res Commun 2001, 283:297-302

15. Ding SJ, Li Y, Shao XX, Zhou H, Zeng R, Tang ZY, Xia QC: Proteome analysis of hepatocellular carcinoma cell strains. MHCC97-H and MHCC97-L, with different metastasis potentials. Proteomics 2004, 4:982-994

16. Alaiya A, Roblick U, Egevad L, Carlsson A, Franzen B, Volz D, Huwendiek S, Linder S, Auer G: Polypeptide expression in prostate hyperplasia and prostate adenocarcinoma. Anal Cell Pathol 2000, 21:1-9

17. Alfonso P, Nunez A, Madoz-Gurpide J, Lombardia L, Sanchez L, Casal Jl: Proteomic expression analysis of colorectal cancer by twodimensional differential gel electrophoresis. Proteomics 2005, 5:2602-2611

18. Hellman K, Alaiya AA, Schedvins K, Steinberg W, Hellstrom AC, Auer G: Protein expression patterns in primary carcinoma of the vagina. Br J Cancer 2004, 91:319-326

19. Kageyama S, Isono T, Iwaki H, Wakabayashi $Y$, Okada Y, Kotani K, Yoshimura K, Terai A, Arai Y, Yoshiki T: Identification by proteomic analysis of calreticulin as a marker for bladder cancer and evaluation of the diagnostic accuracy of its detection in urine. Clin Chem 2004, 50:857-866

20. Kageyama S, Isono T, Matsuda S, Ushio Y, Satomura S, Terai A, Arai Y, Kawakita M, Okada Y, Yoshiki T: Urinary calreticulin in the diagnosis of bladder urothelial carcinoma. Int J Urol 2009, 16:481-486

21. Chen CN, Chang CC, Su TE, Hsu WM, Jeng YM, Ho MC, Hsieh FJ, Lee $\mathrm{PH}, \mathrm{Kuo} \mathrm{ML}$, Lee $\mathrm{H}$, Chang KJ: Identification of calreticulin as a prognosis marker and angiogenic regulator in human gastric cancer. Ann Surg Oncol 2009, 16:524-533

22. Wang Y, Liu J, Smith E, Zhou K, Liao J, Yang GY, Tan M, Zhan X: Downregulation of missing in metastasis gene (MIM) is associated with the progression of bladder transitional carcinomas. Cancer Invest 2007, 25:79-86 
23. Kleeff J, Kornmann M, Sawhney H, Korc M: Actinomycin D induces apoptosis and inhibits growth of pancreatic cancer cells. Int J Cancer 2000, 86:399-407

24. Gold LI, Eggleton P, Sweetwyne MT, Van Duyn LB, Greives MR, Naylor SM, Michalak M, Murphy-Ullrich JE: Calreticulin: non-endoplasmic reticulum functions in physiology and disease. FASEB $J$ 2010, 24:665-683

25. Schardt JA, Eyholzer M, Timchenko NA, Mueller BU, Pabst T: Unfolded protein response suppresses CEBPA by induction of calreticulin in acute myeloid leukaemia. J Cell Mol Med 2010, 14:1509_ 1519

26. Boden G, Merali S: Measurement of the increase in endoplasmic reticulum stress-related proteins and genes in adipose tissue of obese, insulin-resistant individuals. Methods Enzymol 2011, 489: 67-82

27. Lee JY, Chang JW, Yang WS, Kim SB, Park SK, Park JS, Lee SK: Albumin-induced epithelial-mesenchymal transition and ER stress are regulated through a common ROS-c-Src kinase-mTOR pathway: Effect of imatinib mesylate. Am J Physiol Renal Physiol 2011, 300 : F1214-F1222

28. Pike SE, Yao L, Jones KD, Cherney B, Appella E, Sakaguchi K, Nakhasi H, Teruya-Feldstein J, Wirth P, Gupta G, Tosato G: Vasostatin, a calreticulin fragment, inhibits angiogenesis and suppresses tumor growth. J Exp Med 1998, 188:2349-2356

29. Pike SE, Yao L, Setsuda J, Jones KD, Cherney B, Appella E, Sakaguchi K, Nakhasi H, Atreya CD, Teruya-Feldstein J, Wirth P, Gupta G, Tosato G: Calreticulin and calreticulin fragments are endothelial cell inhibitors that suppress tumor growth. Blood 1999, 94:2461-2468

30. Cai KX, Tse LY, Leung C, Tam PKH, Xu RA, Sham MH: Suppression of lung tumor growth and metastasis in mice by adeno-associated virus-mediated expression of vasostatin. Clin Cancer Res 2008, 14 939-949

31. Mesaeli N, Phillipson C: Impaired p53 expression, function, and nuclear localization in calreticulin-deficient cells. Mol Biol Cell 2004 15:1862-1870

32. Lim S, Chang W, Lee BK, Song H, Hong JH, Lee S, Song BW, Kim HJ, Cha MJ, Jang Y, Chung N, Choi SY, Hwang KC: Enhanced calreticulin expression promotes calcium-dependent apoptosis in postnatal cardiomyocytes. Mol Cells 2008, 25:390-396

33. Nanney LB, Woodrell CD, Greives MR, Cardwell NL, Pollins AC, Bancroft TA, Chesser A, Michalak M, Rahman M, Siebert JW, Gold LI: Calreticulin enhances porcine wound repair by diverse biological effects. Am J Pathol 2008, 173:610-630
34. Liu MH, Imam H, Oberg K, Zhou YH: Gene transfer of vasostatin, a calreticulin fragment, into neuroendocrine tumor cells results in enhanced malignant behavior. Neuroendocrinology 2005, 82:1-10

35. Szabo E, Feng TS, Dziak E, Opas M: Cell adhesion and spreading affect adipogenesis from embryonic stem cells: the role of calreticulin. Stem Cells 2009, 27:2092-2102

36. Rojiani MV, Finlay BB, Gray V, Dedhar S: In vitro interaction of a polypeptide homologous to human Ro/Ss-A antigen (calreticulin) with a highly conserved amino acid sequence in the cytoplasmic domain of integrin alpha subunits. Biochemistry 1991, 30:9859-9866

37. Leunghagesteijn CY, Milankov K, Michalak M, Wilkins J, Dedhar S: Cell attachment to extracellular matrix substrates is inhibited upon downregulation of expression of calreticulin, an intracellular integrin alpha-subunit-binding protein. J Cell Sci 1994, 107:589-600

38. Elton CM, Smethurst PA, Eggleton P, Farndale RW: Physical and functional interaction between cell-surface calreticulin and the collagen receptors integrin alpha 2 beta 1 and glycoprotein $\mathrm{VI}$ in human platelets. Thromb Haemost 2002, 88:648-654

39. Coppolino M, Leunghagesteijn C, Dedhar S, Wilkins J: Inducible interaction of integrin alpha 2 beta 1 with calreticulin. Dependence on the activation state of the integrin. J Biol Chem 1995, 270:2313223138

40. Rathinam R, Alahari SK: Important role of integrins in the cancer biology. Cancer Metast Rev 2010, 29:223-237

41. Alur M, Nguyen MM, Eggener SE, Jiang F, Dadras SS, Stern J, Kimm S, Roehl K, Kozlowski J, Pins M, Michalak M, Dhir R, Wang Z Suppressive roles of calreticulin in prostate cancer growth and metastasis. Am J Pathol 2009, 175:882-890

42. Wu MFF, Bai XYY, Xu G, Wei JCC, Zhu T, Zhang YT, Li Q, Liu P, Song AP, Zhao LP, Gang C, Han ZQ, Wang SX, Zhou JF, Lu YP, Ma D: Proteome analysis of human androgen-independent prostate cancer cell lines: variable metastatic potentials correlated with vimentin expression. Proteomics 2007, 7:1973-1983

43. Hanks SK, Ryzhova L, Shin NY, Brabek J: Focal adhesion kinase signaling activities and their implications in the control of cell survival and motility. Front Biosci 2003, 8:D982-D996

44. Daniel JM, Reynolds AB: Tyrosine phosphorylation and cadherin/ catenin function. Bioessays 1997, 19:883-891

45. Schaller MD: Paxillin: a focal adhesion-associated adaptor protein Oncogene 2001, 20:6459-6472

46. Cai H, Zhang T, Tang WX, Li SL: [Expression of paxillin in breas cancer cell with high and low metastatic potentiality]. Chinese. Sichuan Da Xue Xue Bao Yi Xue Ban 2010, 41:91-94

47. Hanks SK, Polte TR: Signaling through focal adhesion kinase. Bioessays $1997,19: 137-145$ 